\title{
Christiane Deloince-Louette, Le premier Homère français: les «Iliades» de Jehan Samxon (1530)
}

\section{Filippo Fassina}

\section{(2) OpenEdition}

1 Journals

\section{Edizione digitale}

URL: https://journals.openedition.org/studifrancesi/21106

DOI: 10.4000/studifrancesi.21106

ISSN: 2421-5856

\section{Editore}

Rosenberg \& Sellier

\section{Edizione cartacea}

Data di pubblicazione: 1 décembre 2019

Paginazione: 564

ISSN: 0039-2944

\section{Notizia bibliografica digitale}

Filippo Fassina, «Christiane Deloince-Louette, Le premier Homère français: les «lliades» de Jehan Samxon (1530)», Studi Francesi [Online], 189 (LXIII | III) | 2019, online dal 01 mars 2020, consultato il 11 novembre 2021. URL: http://journals.openedition.org/studifrancesi/21106 ; DOI: https://doi.org/ 10.4000/studifrancesi.21106

Questo documento è stato generato automaticamente il 11 novembre 2021.

\section{(c)}

Studi Francesi è distribuita con Licenza Creative Commons Attribuzione - Non commerciale - Non opere derivate 4.0 Internazionale. 


\title{
Christiane Deloince-Louette, Le premier Homère français: les «Iliades» de Jehan Samxon (1530)
}

\author{
Filippo Fassina
}

\section{NOTIZIA}

Christiane Deloince-Louette, Le premier Homère français: les «Iliades» de Jehan Samxon (1530), «Bibliothèque d'Humanisme et Renaissance» LXXX, 3, 2018, pp. 507-524.

1 La traduzione cinquecentesca dell'Iliade elaborata da Jehan Samxon offre un interessante esempio delle strategie messe in atto per rendere appetibile a un pubblico aristocratico una materia vasta ed eterogenea come quella dei poemi omerici. Nel 1519, data della traduzione del primo libro, il testo omerico greco circola già abbondantemente in Francia. Tuttavia, Samxon non si serve direttamente dell'originale, ma fa uso di un intermediario latino, la traduzione di Lorenzo Valla del 1440. Inoltre, accanto a quello di Omero, vengono impiegati anche testi di altri autori (Guyon de Coulonne, Darès le Phrygien e Dictys de Crète), che offrono una ricostruzione completa della guerra di Troia e rendono la traduzione di Samxon un testo con pretese anche storiografiche. Quest'opera, che può sembrare all'apparenza ibrida, in realtà mantiene una certa coerenza, poiché distingue la materia omerica da quella del ciclo troiano: infatti, ciascun libro dell'Iliade è nettamente separato dal resto ed è preceduto da una gravure, che dà una posizione di rilievo al testo antico all'interno della più ampia traduzione. L'A. sottolinea dunque che il motivo della scelta di mescolare Omero ad altri autori è motivata dal fatto che il pubblico a cui è indirizzata l'opera di Samxon non si sarebbe accontentato del singolo episodio narrato nell'Iliade. Il traduttore avrebbe dunque cercato di soddisfare questa aspettativa inserendo anche la narrazione delle cause e degli effetti della guerra di Troia e offrendone una ricostruzione storica completa. Dal punto di vista del metodo traduttologico, l'A. fornisce alcuni esempi per dimostrare come Samxon, da una parte, sia molto fedele a Valla, ma, allo stesso tempo, 
inserisca numerose amplificazioni retoriche che hanno la finalità di mettere in rilievo alcuni argomenti o episodi particolarmente significativi. Nel complesso, viene evidenziato come questo volgarizzamento cerchi di introdurre nella prosa francese una dimensione poetica in grado di rivaleggiare con i grandi umanisti italiani. La scelta di Omero è dunque anche scelta polemica di un autore francese che vuole appropriarsi di un genere letterario - quello epico antico - che era appannaggio degli italiani, e che cerca di dar lustro alla lingua francese in un periodo in cui questa si sta ricavando un spazio autonomo nel panorama culturale e letterario europeo. 